\title{
Evaluation of IMNCI Practices among Health Care Providers in a District of North India.
}

\author{
J. Venkatachalam ${ }^{1}$, Arun Kumar Aggarwal ${ }^{2}$, Madhu Gupta, ${ }^{3}$ G.R.Sathya ${ }^{4}$. \\ 1,Assistant professor, Dept of community medicine, Pondicherry Institute of Medical sciences, Kalapet, \\ Pondicherry -605014. \\ 2, Professor of Community Medicine, Post Graduate Institute of Medical Sciences and Research, Chandigar-12. \\ 3.Assistant professor Dept of community medicine, Post Graduate Institute of Medical Sciences and \\ research, Chandigarh -12 . \\ 4, Post Graduate, Dept of Physiology, Pondicherry Institute of Medical Sciences. Pondicherry.
}

\begin{abstract}
Objective
1. To study the adherence of HSPs to IMNCI guidelines for managing childhood diseases.

2. To ascertain the knowledge regarding danger signs of under fives' in study population

Material and Methods: A cross sectional study was carried out in a district of Panchkula in 2010. Multistage random sampling was used for selection of study population. 588 parents of under-five children were interviewed by using a pretested validated questionnaire. The data regarding adherence health workers to IMNCI guidelines for management common under fives illness was collected from parents. Data entry and analysis was done using SPSS 16.0.

Result:

IMNCI strategy was implemented in the district of Panchkula in 2007. In 2010 we assessed the adherence of health care providers to IMNCI guidelines in two blocks of Panchkula for managing under-five children. Three fourth of the children were examined by health care providers for acute respiratory infections among which respiratory rate was counted for full one minute in only 50\% of the children. Regarding adherence to fever management $94 \%$ of the children were checked for temperature, $60 \%$ examined for neck stiffness and $31.4 \%$ of children's mothers were enquired about rash. Regarding adherence to diarrhea management of the $93.3 \%$ of the children who were assessed for dehydration, only $40 \%$ children were advised to take extra feeding/ extra fluids, $66 \%$ were advised to take ORS.

Conclusion: Adherence of IMNCI guidelines for management of under five children was not satisfactory after implementation IMNCI.
\end{abstract}

Key words:- health seeking behavior, under- five, IMNCI.

\section{Introduction}

Government of India (GOI) has been doing a lot of efforts to improve the community treatment seeking practice and skills and knowledge of health care providers by introducing many child health programmes since last three decades. In 1978, Diarrheal Disease Control Programme (DDCP) was launched in India. In 1985-86, the focus shifted to strengthening case management of diarrhea for children under age of five years and National Oral Rehydration Therapy (ORT) Programme was introduced. Subsequently, DDCP and ARI control programme (initiated in 1989-90) became part of Child Survival and Safe Motherhood Programme in 1992 and Reproductive and Child Health (RCH) Programme in 1997. WHO/UNICEF proposed Integrated Management of Childhood illnesses (IMCI) in 2005 in RCH-2 2.

Due to very high neonatal mortality, India has further amended this strategy by including management of neonatal illnesses and the strategy was renamed as Integrated Management of Neonatal and Childhood Illness (IMNCI). The IMNCI programme was introduced in India in the year 2005, under National Rural Health Mission. In district Panchkula, the IMNCI training was given to health care providers Anganwadi Workers(AWWs), ANMs and medical officers in the year 2006. The objective of training was to improve knowledge and practices of health care providers. So this study was carried out to ascertain how far IMNCI guidelines was practiced by health service providers in the community.

\section{Materials And Methods}

Cross sectional study design was carried out in a district of Panchkula. It comprises two sub divisions and two Community development blocks namely Raipur Rani and Kalka. There are 111 villages in Raipur Rani block and 125 in Kalka block. Area of the district is $898 \mathrm{sq} \mathrm{km}$, and the total population is 4,69,210. Infrastructure wise this district has a district hospital, two community health centres (CHCs) in region of Raipur Rani and Kalka. There are 47 total sub centres (19 in Raipur Rani and 28 in Kalka block. Study Population - 
Families having children between 0-5 years of age group. Sample size was calculated using Epi Info statistical software with assumption that $25 \%$ of ill children were receiving adequate care from the public health facilities; it was also assumed that one fourth of children would be having diarrhea, cough and fever. Other parameters were precision of $10 \%$, design effect $2, \alpha$ at $5 \%$, and $95 \%$ confidence interval . Multistage simple random sampling technique was used to assess the health care providers IMNCI Practices. One sub-centre was selected randomly in each PHC. In each selected sub-centre, one village was selected randomly. After selecting first house randomly in the selected village, all consecutive houses were visited till required sample was achieved in the village. In case of non availability of family at the time of first visit, revisit was done. In case family is not available on second visit also, then this family was dropped from the sample and replacement was done from consecutive houses. In each village 84 parents/responsible respondent in the family of children (0-5years) was interviewed, (fig-1). Study Tools: A semi structured pretested validated questionnaire was administered. Statistical analysis Descriptive statistics like percentage and Chi-square test was used to estimate the difference in proportion regarding Primary health care providers IMNCI practices in two blocks of Panchkula. The study was analyzed using SPSS 16.0 version. P value of 0.05 was considered significant. Informed consent of participants was taken before enrolling them in the study. Participant's individual identifying information was kept confidential, and was used for research purpose.

\section{Demographic profile.}

\section{Result}

588 under five cases were interviewed from parents of under-five children, out of which 358(60.9\%) were male and 230(39.1\%) were female. Of the 252 were from Raipur Rani block and 336 from Kalka block. About $3.6 \%$ of the children were in the age of $0-2$ months, $24 \%$ were in the age of $3-12$ months, $22.5 \%$ in the age group of 13-24 months, $17.2 \%$ belonged to $25-36$ months, $17.7 \%$ were age group of 37-48 months and $15 \%$ were in the age group of 49-60 months respectively. Among 588 children 95(16.1\%), 105(17.8\%), 64(10.9) had ARI, Fever, Diarrhea respectably preceding last two weeks. Majority 493(83.8\%) of the children were residing in pucca houses, semi pucca $88(15 \%)$ few of them living in kachha $7(1.2 \%)$ houses.

\section{IMNCI practices of Health Care Providers for ARI}

Out of 95 children who had ARI all were taken to HSPs. Overall 74 (77.9\%) of the children's chest was exposed for counting the respiratory rate in both the blocks. Respiratory rate was counted for full one minute in $45(47.4 \%)$ of the children and for less than one minute $28(29.8 \%)$. In $22 \%$ of the children the respiratory rate was not counted at all. Twenty percent of the children were treated only with medicines and rest $80 \%$ were treated by giving medicines with counseling. None of the children were referred to higher facility nor treated only with counseling. There was no statistical significant $(\mathrm{P}>0.05)$ difference in treating ARI in two blocks of Panchukula. (Table-1)

Table-1: IMNCI practices for treating ARI in district Panchkula.

\begin{tabular}{|l|l|l|l|l|}
\hline \multirow{2}{*}{ Health care practices } & $\begin{array}{l}\text { Raipur Rani } \\
(\mathbf{N = 2 7})\end{array}$ & $\begin{array}{l}\text { Kalka } \\
(\mathbf{N}=\mathbf{6 8})\end{array}$ & $\begin{array}{l}\text { Total } \\
\mathbf{N}=\mathbf{9 5}\end{array}$ & \multirow{2}{*}{ P value } \\
\cline { 2 - 4 } & $\mathrm{n}(\%)$ & $\mathrm{n}(\%)$ & $\mathrm{n}(\%)$ & \\
\hline $\begin{array}{l}\text { Chest exposed for respiratory } \\
\text { rate counting }\end{array}$ & $23(85.2)$ & $51(75.0)$ & $74(77.9)$ & \multirow{2}{*}{0.28} \\
\hline Respiratory rate counted for & $14(51.9)$ & $31(45.6)$ & $45(47.4)$ & \multirow{2}{*}{0.47} \\
\hline One minute & $9(33.3)$ & $19(27.9)$ & $28(29.8)$ & \\
\hline Less than one minute & $4(14.8)$ & $18(26.5)$ & $22(23.2)$ & \\
\hline Not at all counted & \multicolumn{3}{|l|}{} \\
\hline Management of illness & $3(11.1)$ & $16(23.5)$ & $19(20.0)$ & 0.17 \\
\hline Drug only
\end{tabular}

V. IMNCI practices of health care providers for fever.

Out of 109 children who had fever, 105(90.1\%) children were taken to health facility. Among which 99 (94.3) \% of the children's temperature was checked. About 63(60\%) of the children were checked for neck stiffness. 33(31.4\%) of the children's mothers were asked for the history of rash. The children who had fever were managed with medicines only 33(31.4\%) and medicines with counseling 72(68.6\%). (tab-3) 
Evaluation Of IMNCI Practices Among Health Care Providers In A District Of North India.

Tab-3, IMNCI practices of health service providers for fever management.

\begin{tabular}{|c|c|c|c|c|}
\hline \multirow[t]{2}{*}{ Practices } & $\begin{array}{l}\text { Raipur Rani } \\
\mathrm{N}=51\end{array}$ & $\begin{array}{l}\text { Kalka } \\
\mathrm{N}=54\end{array}$ & $\begin{array}{l}\text { Total } \\
\mathrm{N}=105\end{array}$ & \multirow[t]{2}{*}{$P$ value } \\
\hline & $\mathrm{n}(\%)$ & $\mathrm{n}(\%)$ & $\mathrm{n}(\%)$ & \\
\hline Checked Temperature & 48 (94.1) & $51(94.4)$ & 99 (94.3) & 0.967 \\
\hline Checked neck stiffness & $24(47.1)$ & $39(72.2)$ & $63(60)$ & 0.129 \\
\hline Enquired about rash & $12(23.5)$ & $21(38.9)$ & $33(31.4)$ & 0.328 \\
\hline \multicolumn{5}{|l|}{ Management of illness } \\
\hline Medicine only & $18(33.3)$ & $15(27.8)$ & $33(31.4)$ & 0.632 \\
\hline Medicine and counseling & $33(64.7)$ & $39(72.2)$ & $72(68.6)$ & 0.632 \\
\hline
\end{tabular}

\section{IMNCI practices among health service providers for diarrhoea management}

Out of 64 children who had diarrhea, 56(93.8\%) of children were taken to HSPs, out of which $93.3 \%$ of the children's dehydration was assessed by pinching the abdominal wall. Forty percent of them were advised to give extra feeding/extra fluids to the children, $66.7 \%$ of the mothers were advised to give ORS and were told how much to give. Preparation of ORS was demonstrated to only $26.7 \%$ of the mothers and $21.4 \%$ of the mothers were advised about how much ORS should be given. The children who had diarrhea were managed with only medicine in $46.7 \%$ of the cases and counseling was done along with medicines $53.3 \%$ of the cases. (tab-4)

\begin{tabular}{|l|l|l|l|l|}
\hline Practices & $\begin{array}{l}\text { Raipur Rani } \\
\mathrm{N}=44\end{array}$ & $\begin{array}{r}\text { Kalka } \\
\mathrm{N}=20\end{array}$ & $\begin{array}{l}\text { Total } \\
\mathrm{N}=64\end{array}$ & \multirow{2}{*}{ P value } \\
\cline { 2 - 4 } & $\mathrm{n}(\%)$ & $\mathrm{n}(\%)$ & $\mathrm{n}(\%)$ & \\
\hline Pinch the abdominal wall & $40(90.9)$ & $16(100)$ & $56(93.3)$ & 0.53 \\
\hline Extra feeding /extra fluids & $16(36.4)$ & $8(50)$ & $24(40)$ & 0.63 \\
\hline Ors advised & $24(54.5)$ & $16(100)$ & $40(66.7)$ & 0.12 \\
\hline Demonstrated & $12(27.3)$ & $4(25)$ & $16(26.7)$ & 0.93 \\
\hline How much should given & $24(54.5)$ & $16(100)$ & $40(66.7)$ & 0.83 \\
\hline Management & \multicolumn{3}{|l|}{} \\
\hline Drug with counseling & $20(45.5)$ & $12(75)$ & $32(53.3)$ & 0.66 \\
\hline
\end{tabular}

Table-4, IMNCI Practices Among Health Service Providers for Diarrhoea Management.

VII. Knowledge about danger signs among parents of under five children.

Over all, out of the 164 children who were suffering from various illness in Panchkula district, 144 $(87 \%)$ children were taken to the health facilities. Among the 144 care givers $86.8 \%$ were explained about the conditions as when the children have to be taken to the hospital. About $57 \%$ of parents who were about general dangers sign (Raipur Rani $-65.4 \%$, Kalka- 50\%). $70.6 \%$ of the parents were satisfied averagely and $28 \%$ were very much satisfied about the treatment only $1.4 \%$ were not satisfied. Table-5.

Table-:5 Knowledge About Danger Signs and Their Level of Satisfaction.

\begin{tabular}{|c|c|c|c|c|}
\hline \multirow[t]{2}{*}{ IMNCI practices } & $\begin{array}{l}\text { Raipur Rani } \\
(\mathrm{N}=52)\end{array}$ & $\begin{array}{l}\text { Kalka } \\
(\mathrm{N}=92)\end{array}$ & $\begin{array}{l}\text { Total } \\
(\mathrm{N}=144)\end{array}$ & \multirow[t]{2}{*}{$\mathrm{P}$ value } \\
\hline & $\mathrm{n}(\%)$ & $\mathrm{n}(\%)$ & $\mathrm{n}(\%)$ & \\
\hline $\begin{array}{l}\text { Advised when should the child be } \\
\text { taken to hospital }\end{array}$ & $46(88.5)$ & $79(85.9)$ & $125(86.8)$ & 0.87 \\
\hline \multicolumn{4}{|c|}{ Status of danger signs explained to mothers } & \\
\hline No danger signs explained & 7 (13.5) & $13(12)$ & $19(13.2)$ & \multirow{3}{*}{0.13} \\
\hline 1-2 danger signs explained & $12(21.2)$ & $34(37)$ & $46(31.2)$ & \\
\hline 3-5 danger signs explained & $34(65.4)$ & $46(50)$ & $80(55.4)$ & \\
\hline \multicolumn{4}{|l|}{ Level of satisfaction of mothers } & \\
\hline Average & $37(72.5)$ & $64(69.6)$ & $101(70.6)$ & \multirow{3}{*}{0.12} \\
\hline Very much & $12(23.5)$ & $28(30.4)$ & $40(28)$ & \\
\hline Nat satisfied & $2(3.9)$ & $0(0)$ & $2(1.4)$ & \\
\hline
\end{tabular}




\section{Discussion}

IMNCI strategy is holistic approach that has improved health service provider's knowledge and skills. Most of the community based studies showed that after implementation of IMNCI their knowledge, skills and their practices improved. However the present study evaluates the adherence of were health care providers to IMNCI guidelines after three years of IMNCI implementation. This study revealed that the HSPs adherence to IMNCI guidelines for managing under-illness, ie ARI, diarrhea, fever were found to be inadequate. This was possibly due to poor supportive supervision, non-practicing IMNCI module while seeing the child.

A study in Ballabgarh also showed that attained knowledge and skills may decline over a period of time among health workers 6 . A study in Tanzania also showed poor adherence to IMCI guidelines for managing under-five children after IMCI training.?

A community based study conducted in Rajasthan quoted that after IMCI training given to doctors in intervention area, $15 \%$ of intervention group mothers and $10 \%$ of control group mothers sought care from an appropriate provider promptly; one month after training, intervention site doctors counselled more effectively than control group doctors, but at six months their performance had declined ${ }^{8 .}$ Our previous study also showed that the HSPs knowledge and skills was improved immediately after IMNCI training but it was declined over a period of time $\mathrm{e}^{9,10}$.

With respect to general dangers sign more than half of the mothers (55.4\%) were explained about the 3-5 general dangers signs like lethargy or unconscious, inability to feed /drink, vomiting everything, convulsion by HSPs. Mankar MJ et $\mathrm{al}^{11}$, and Sreeramareddy CT et $\mathrm{al}^{12}$ also study finding showed that about less than half of the mothers recalled at least two dangers signs. This study concludes that our Health Service Providers practicing IMNCI guidelines slightly better than the above mentioned area. However this practice needs to improve in both areas. WHO also emphasizes that the integrated management of childhood illness (IMCI) strategy, besides improving providers' skills in managing childhood illness it also aims to improve families' care seeking behaviour. The health workers are trained to teach the mothers about danger signs and counsel them about the need to seek care promptly if these signs occur ${ }^{13}$.

For effective skill retention, there is a need to strengthen implementation of IMNCI with specific attention to supportive supervision, timely refresher courses, maintenance of constant drug supply, strong referral mechanism and general system strengthening ${ }^{14,15}$.

\section{Contributions:-}

Venkatachalam J: Conception and design of the study; planning and conducting the study; analysis and interpretation of data; and drafting the paper. Aggarwal KA: Conception and design of the study; providing guidance; and revising the draft critically for substantial intellectual content. Gupta M: Conception and design of the study; and revising the draft critically for substantial intellectual content. Sathya GR: Data collection and revising the draft critically for substantial intellectual content.

Conflict of Interest:- None.

Role of Funding Source Project Director, Reproductive and Child

Health-II (RCH-II), District Panchkula, Haryana, provided support for this project.

Acknowledgements:-

The authors would like to thank Project Director, Reproductive and Child Health II (RCH II), district Panchkula, Haryana, India, for providing financial support for this work, Dr. Dinesh Kumar and Dr. Murali Mohan Reddy for providing timely suggestions during the design and conduct of the study. In addition, the author wants to thanks driver Mr.Harminder Singh for providing timely transport help during data collection.

\section{References}

[1] State of the world's children 2008.UNICEF House, UNICEF, New York. Available at www.unicef.org. Accessed on 20/10/08

[2] International Institute for Population Sciences (IIPS) and ORC Macro 2000. National Family Health Survey (NFHS-3), India, 2006.

[3] Sample Registration System (SRS), SRS Bulletin 2009. Available at www.censusindia.gov.in. Accessed on 21/11/08.

[4] Dongre AR, Deshmukh PR, Garg BS. Perceptions and health care seeking about newborn danger sign among mothers in rural Wardha. Indian J Pediatr 2008;75:325-9.

[5] Bandyopadhyay S, Kumar R, Singhi S, Aggarwal A. Are primary health care workers skilled enough to assess the severity of illness among young infants? Indian Pediatric 2003; 40:713-18.

[6] Anand K, Patro BK, Paul E, Kapoor SK. 2004. Management of sick children by health workers in Ballabgarh: lessons for implementation of IMCI in India. J Trop Pediatr 2004;50(1): 41-7.

[7] Nicholas D Walter, Thomas Lyimo, Jacek Skarbinski, Emmy Metta, Elizeus Kahigwa, Brendan Flannery, et al. Why first-level health workers fail to follow guidelines for managing severe disease in children in the Coast Region, the United Republic of Tanzania. World Health Organ 2009;87:99-107 | doi:10.2471/BLT.08.050740.

[8] Mohan P, Iyengar SD, Martines J, Cousens S, Sen K. Impact of counseling on care seeking behavior in families with sick children cluster randomized trail in rural India. BMJ 2004;329:266.

[9] Kumar D,Aggarwal AK, Kumar R. The effect of interrupted 5day training on IMNCI on the knowledge and skills of primary health care workers. Health policy plan. 2009;24:94-100.

[10] Venkatachalam J, Kumar D, Gupta M , Aggarwal AK. Knowledge and skills of primary health care workers trained on IMNCI : Follow up assessment 3 years after training. Indian journal of public health.2011;55:298-302. 
Evaluation Of IMNCI Practices Among Health Care Providers In A District Of North India.

[11] Mankar MJ, Mehendale AM, Garg BS. A Role of Integrated Management of Childhood Illness (IMCI) Strategy for Changing Child Rearing Practices at Household and Community Level. Bombay Hospital Journal 2008; 50: (4).

[12] Sreeramareddy CT, Shankar RP, Sreekumaran BV et al. Care seeking behaviour for childhood illness- a questionnaire survey in western Nepal. BMC International Health and Human Rights 2006, 6:7 doi:10.1186/1472-698X-6-7.

[13] World Health Organization: Counsel the mother: management of childhood illnesses. Geneva: WHO; 1997.Venkatachalam J, Kumar D, Gupta M, Aggarwal AK. Development of One day Refresher Training Course for Primary Health Care Workers on IMNCI. Indian Journal of Public Health Research \& Development (accepted on 10/2/2012.)

[14] Hemant D. Shewade \& Arun K. Aggarwal \& Bhavneet Bharti. Integrated Management of Neonatal and Childhood Illness (IMNCI): Skill Assessment of Health and Integrated Child Development Scheme (ICDS) Workers to Classify Sick Under-five Children. Indian J Pediatr DOI 10.1007/s12098-012-0835-4. 